

\title{
Editorial
}

\section{Violence against paramedics - when will it stop?}

\author{
Malcolm Boyle PhD', Jaime Wallis BEH(Paramedic) ${ }^{1}$
}

\author{
Affiliation: \\ ${ }^{1}$ Monash University, Victoria
}

Welcome to the first issue of the Australasian Journal of Paramedicine for 2016. We start this year's first editorial with what is making headlines around Australia: acts of violence against paramedics.

These unacceptable acts of belligerence and disrespect towards paramedics appear to be on the rise with several reports featuring in prominent media outlets around Australia. (1-3). The disturbing and most disheartening aspect to this surge in violence towards paramedics is that the primary aim of the paramedic is to manage the sick or injured patient in a safe environment. Paramedics are there to help and assist in the event of an emergency, not be on the receiving end of various acts of violence. In due course these acts diminish the job satisfaction, gratification and joy that ambulance paramedics should experience in their employment. Not to mention a safe working environment that everyone has the right to.

In 1993 paramedic exposure to workplace violence was first reported by Tintinalli in the scientific literature (4) with the only Australian study into paramedic exposure to workplace violence published in 2007 (5). The study by Boyle et al identified that the main perpetrators of violent acts again paramedics were the patient, the patient's relative or friend with most of these perpetrators being male (6). The paramedics thought that drugs and/or alcohol were contributing factors to the acts of violence against them (6), this still appears to be true.

A concern to academic institutions is the potential for paramedic students to be exposed to acts of violence whilst undertaking clinical placements with ambulance services and other healthcare providers. An Australian study presented at the Third International Conference on Violence in the Health Sector found that paramedic students were exposed to acts of workplace violence during their clinical placement, however, some of these acts were perpetrated by the paramedics and other staff they were working with (7). One of the issues with student paramedic exposure to acts of violence is the student's lack of desire to report the incident to appropriate staff, something that requires further investigation.

Educational institutions need to better prepare students to deal with workplace violence when they encounter it and this education process needs to continue onto the ambulance service when they are employed as a graduate paramedic. How this preparation of students occurs is still open to some debate, especially where it fits within the tertiary educational curriculum, ambulance induction program, graduate year or on the job exposure and experience.

Even though most states in Australia have varying length jail penalties for people who commit acts of violence against paramedics during the course of their work, it would appear this penalty is not a complete deterrent. The South Australian Government launched a media campaign in an attempt to arrest the increasing number of attacks on paramedics (8). The problem with a perpetrator of violence against a paramedic is that if the perpetrator is affected by alcohol and/or drugs, they are often not thinking clearly or may lack the ability to comprehend and act on instructions they are given by paramedics.

It remains to be seen if this increase of violence against paramedics continues unabated or multiple campaigns like the one in South Australia and significant jail terms have some influence on the perpetrators.

The increase in violent episodes may be due, in part, to the time of the year when people are consuming more alcohol during the holiday season or an increased use of ICE (crystal methamphetamine). Or could it be that we are witnessing a shift in a lack of respect for paramedics or a distortion of unspoken societal rules and norms that we do no harm to people that are attempting to help or assist us. Either way you choose to look at this issue, these acts of violence against paramedics need to stop, whether this happens through increased awareness, educational interventions or stronger penalties. The time to act is now. 
In this issue there are four articles covering various aspects of the paramedicine/pre-hospital setting. The article by Ross and colleagues from Monash University investigates what motivating factors influenced students to enrol in a paramedic course (9). The article by Edwards and colleagues investigates anaphylaxis presentations to the Tasmanian Ambulance Service and which cases are administered adrenaline prior to ambulance arrival. This article is one of very few pre-hospital related anaphylaxis studies that report on adrenaline administration (10). The article by Johnston and Acker explores the move to professionalism and the identity of the paramedic using a sociological approach based on prominent social theorists (11). The final article by Lenson and Mills is a literature review investigating the ability of school children to retain first aid knowledge and skills (12).

Dr Mal Boyle

Editor

Australasian Journal of Paramedicine

Jaime Wallis

Department of Community Emergency Health \& Paramedic Practice

Monash University

\section{References}

1. Banks K. Female paramedic attacked while saving patient's life, continues treating him while injured. NT News. 1 January 2016. Available at: www.ntnews.com.au/news/northern-territory/female-paramedic-attacked-while-saving-patients-life-continuestreating-him-while-injured/news-story/ae0cb909d9c38b927d55323fef81f94f

2. Zielinski C. Vic paramedic assaulted on duty. Melbourne: 7 News; 2015. Available at: www.news.com.au/national/breaking-news/ vic-paramedic-assaulted-on-duty/news-story/a97ca5d20cd7d2a9691b9f52469b198b

3. Diefenbach R. Queensland Paramedic Allegedly Assaulted In Moving Ambulance. The Huffington Post (Australia). 13 December 2015. Available at: www.huffingtonpost.com.au/2015/12/12/qld-paramedic-allegedly-a_n_8794896.html

4. Tintinalli JE, McCoy M. Violent patients and the prehospital provider. Ann Emerg Med 1993;22(8):1276-9.

5. Boyle MJ, Koritsas S, Coles JY, Stanley JR. A pilot study of workplace violence towards paramedics. Emerg Med J 2007;24(11):760-3.

6. Boyle M, Koritsas S, Coles J, editors. Perpetrators of violence against paramedic's in the workplace and the paramedic's response. The Second International Conference on Violence in the Health Sector; 2010; Amsterdam, The Netherlands: Kavanah.

7. Boyle M, McKenna L, editors. Are paramedic and midwifery students exposed to workplace violence during clinical placements? The Third International Conference on Violence in the Health Sector; 2012; Vancouver, Canada: Kavanah.

8. Crouch B. SA Government launches campaign to stop violence against health workers. The Advertiser. 27 May 2015. Available at: www.adelaidenow.com.au/news/south-australia/sa-government-launches-campaign-to-stop-violence-against-health-workers/ news-story/96b3fef311ed6c6433fa639404c02e2a

9. Ross L, Hannah J, Van Huizen P. What motivates students to pursue a career in paramedicine? Australasian Journal of Paramedicine 2016;13(1).

10. Edwards D, Blackhall M, Berry R. Community Presentations of Anaphylaxis in Tasmania: Who is administering the adrenaline? Australasian Journal of Paramedicine 2016;13(1).

11. Johnston T, Acker J. Taking the 'Boring' out of Bourdieu - Using a sociological approach to answering questions relating to paramedic professionalism and identity. Australasian Journal of Paramedicine 2016;13(1).

12. Lenson S, Mills J. First aid knowledge retention in school children: A review of the literature. Australasian Journal of Paramedicine 2016;13(1). 